\title{
PATTERNS OF ACUTE POISONING AMONG PATIENTS TREATED IN THE EMERGENCY WARDS OF A TERTIARY CARE HOSPITAL: A CROSS-SECTIONAL STUDY
}

\author{
DEVI REVATHI", SATHVIKA REDDY ${ }^{1}$, LAKSHMI PRASANNA V ${ }^{1}$, ARUNA C RAMESH ${ }^{2}$
}

\begin{abstract}
${ }^{1}$ Department of Pharmacy Practice, Pharm-D Intern M. S. Ramaiah University of Applied Sciences, Bengaluru, Karnataka, India, ${ }^{2}$ Department of Emergency Medicine, MS Ramaiah Hospitals, Bengaluru, Karnataka, India. Email: Devirevathi.ganni@gmail.com
\end{abstract}

Received: 21 May 2018, Revised and Accepted: 10 July 2018

\section{ABSTRACT}

Objective: Poisoning is a growing health-care burden in developing countries like India. Predicting the nature of the intention behind poisoning and type of poisoning agent involved will help in facilitating appropriate treatment measures, hence, improving the patient's quality of life.

Methods: The prospective, observational study was conducted in a tertiary care multispecialty hospital for 6 months from November 2016 to April 2017 and involved a total of 133 patients. Treatment and outcomes of the patients were collected, documented in a data collection form. Chi-square test and logistic regression analysis were applied.

Results: The mean age of the study participants was $27.76 \pm 15.5$ with predominance seen in age groups of $<30$ years (59.3\%), females ( $52.6 \%$ ), and married (49.6\%). Intentional poisoning (69.1\%) through oral ingestion $(81.2 \%)$ of medications (51.6\%) in solid forms $(60.2 \%)$ was predominant. Patients presenting with systemic manifestations (70.4\%) arrived in a time duration $>1 \mathrm{~h}(66.2 \%)$, received first aid (62.4\%), and supportive care (52.7\%). Higher ingestion of physical forms was significantly observed in both single (OR: 4.5 ) and married (OR: 3 ). The outcomes were correlated with poison severity score and patients with mild symptoms recovered $(60.9 \%)$.

Conclusion: The use of medicines for intentional poisoning continues to be rampant in younger age groups and married individuals. Educational programs with more accentuation on the data regarding toxic substances along with preventive measures are to be implemented to make mindfulness among the overall population.

Keywords: Acute poisoning, Clinic pharmacist, Intentional.

(c) 2018 The Authors. Published by Innovare Academic Sciences Pvt Ltd. This is an open access article under the CC BY license (http://creativecommons. org/licenses/by/4. 0/) DOI: http://dx.doi.org/10.22159/ajpcr.2018.v11i11.27422

\section{INTRODUCTION}

Acute poisoning is a complex public health issue which varies geographically and remains as one of the most common reasons for admission in the emergency departments [1]

Poisoning incidence in India is rising in large numbers; it is observed that more than 50,000 deaths occur as a result of poisoning every year [2]. As per the National Crime Bureau of India, suicides due to poisoning in 2015 were $27.9 \%$ and the most common means adopted for suicides involved drug poisonings [3].

India is an agrarian country where agriculture is the principal source of livelihood for more than $55 \%$ of the population [4,5]. Several studies revealed that pesticides, drugs, and household products account for the major poisoning in India. The incidence of these deliberate poisonings is rising due to the currently fluctuating professional, emotional, and social characteristics [1].

The type of poisoning used in deliberate self-harm is influenced by its easy means of communication and information through media, over the counter sales, prior knowledge about the poisonous agent, and its effects [6]. The course of clinical management and ultimate outcomes of these patients are determined by the type of poisoning agent, the amount of poison consumed, preexisting comorbidities, the time from exposure to the presentation at a health-care facility, and availability of services [7]. Along these lines, the information about clinical features of acute poisoning through a systematic assessment allows early acknowledgment and hospitalization of high risk and critically ill patients [8].

Unavailability of published data on poisoning agents and their outcomes has resulted in scarcity of updated information in the databases of Poison Information Centres in India [8]. Hence, the present study was conducted with an objective to assess the patterns of acute poisoning and their treatment outcomes which can provide a practical guide for the general practitioners, residents, and hospital staff toward the management of acute poisoning.

\section{METHODS}

This hospital-based prospective observational study was approved by the institutional ethics committee (Registration No: ECR/215/Inst/ Ker/2013) and was carried out for 6 months (November 2016 to April 2017 ) in the accident and emergency wards of a tertiary care hospital, Bangalore, located in an urban area.

Considering the number of medicolegal cases presenting to the hospital within 6 months, the survey included a total of 133 acute poisoning cases of known and unknown origin of all ages along with poisoning cases referred from peripheral, local and rural hospitals for further management. The study excluded cases with ingestion of non-digestible substances such as coins, pins and plastics, deliberate self-harm by hanging, self-inflicted wounds, burns and bruises, vehicular accidents, suspected murder, sexual assault, and cases of criminal abortion.

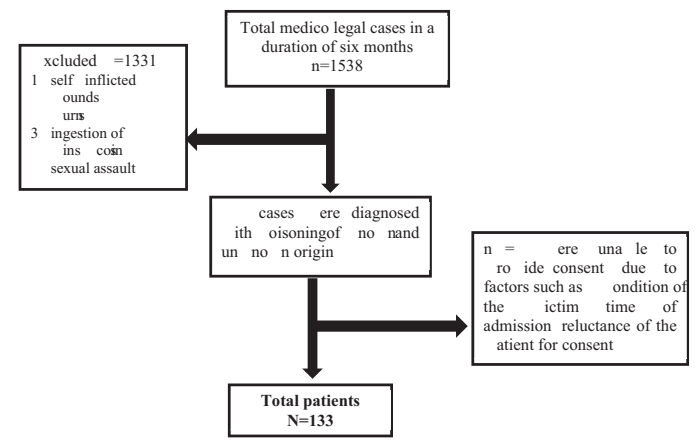


Written informed consent was obtained from the respondents either the patient or the caretakers, and data were collected from patient's case records, medication charts, medicolegal cases registers, selfinterviewing the patient based on their level of consciousness, after receiving first aid in the emergency wards, intensive care unit (ICU), or general wards. Interviewing the caretaker/families regarding the history and circumstances that led to the following situation and information from the health-care professionals regarding the poisoning agent, severity of poisoning, outcomes in the patients contributed meaningfully, and effectively toward the study.

A suitably designed data collection form was used for the recording as follows:

- Demographic details: Age, gender, and marital status.

- Patterns of poisoning: Reason for poisoning, route of poisoning, the intended use of poisoning, and the physical form of the poisoning agent.

- Hospital admission characteristics: Time elapsed from exposure to hospitalization, first aid, symptoms, treatment, therapeutic drugs administered, and prediction of severity of poisoning based on the poison severity score (PSS).

Data collection was done by trained personnel, documented, and transcribed into the database.

Poisoning severity score is a standardized scale for grading the severity of poisoning. It allows qualitative evaluation of morbidity caused by poisoning, better identification of real risks, and comparability of data.

\section{Severity grades}

- None (0): No symptoms or signs related to poisoning

- Minor (1): Mild, transient, and spontaneously resolving symptoms

- Moderate (2): Pronounced or prolonged symptoms

- Severe (3): Severe or life-threatening symptoms

- Fatal (4): Death.

\section{Statistical analysis}

The data collected was entered into an Excel spreadsheet. Data were analyzed using the Statistical Package for the Social Sciences (SPSS) version 22 (SPSS Inc., Chicago, IL, USA). Descriptive and inferential statistics were done. Demographic and hospital attendant variables were categorized and were subjected to analysis. Binary logistic regression was applied to check the relationship between demographic profile and pattern of poisoning. Statistical significance was considered at $\mathrm{p}<0.05$ (confidence interval of $95 \%$ )

\section{RESULTS}

A total of 133 participants were studied. Poisoning was common in age groups of $<30$ years $(59.3 \%)$ with a mean $27.76 \pm 15.5$. Females were $52.6 \%$ while males $(47.3 \%)$. In light with marital status, poisoning was seen in married $(49.6 \%)$ followed by single $(36 \%)$ (Table 1).

Regarding the patterns of poisoning according to the circumstances that lead to toxic exposure, the most common mode of poisoning was intentional (69.1\%) which commonly occurred through oral ingestion $(81.2 \%)$ of solid dosage forms $(60.2 \%)$ while $30.8 \%$ were non-intentional which were accidental $(41.4 \%)$, bee stings $(36.5 \%)$, and snakebites $(22 \%)$. The most frequently encountered poisoning substances comprised pharmaceutical drugs (51.6\%) and household chemicals (34\%) (Table 2).

In regard to the hospital admission characteristics, $66.2 \%$ arrived at the hospital within a time interval $>60 \mathrm{~min}$ and $33.2 \%<60 \mathrm{~min}$. Traffic-related issues $(76.2 \%)$ were the most common reason for the reason for the delay in admission. A total of $82 \%$ poisoning incidents occurred at home $(82 \%)$. The significant clinical signs and symptoms the patients presented at admission were systemic $(70.4 \%)$ including gastrointestinal, neurological, and dermatological manifestations.
Table 1: Demographic variables of the study participants

\begin{tabular}{ll}
\hline Variables & $\mathbf{n = 1 3 3}(\mathbf{\% )}$ \\
\hline Age & \\
Mean age & $27.76 \pm 15.5^{*}$ \\
$<30$ years & $79(59.3)$ \\
$\geq 30$ years & $54(40.6)$ \\
Gender & \\
Male & $63(47.3)$ \\
Female & $70(52.6)$ \\
Marital status & \\
Single & $48(36.0)$ \\
Married & $66(49.6)$ \\
Others & $19(14.2)$ \\
\hline *Mean $\pm S D,{ }^{*}$ n=number of participants, SD: Standard deviation &
\end{tabular}

Table 2: Pattern of poisoning of study participants

\begin{tabular}{ll}
\hline Variable & $\mathbf{n = 1 3 3}(\mathbf{0})$ \\
\hline Reason for poisoning & \\
Intentional & $92(69.1)$ \\
Non-intentional & $41(30.8)$ \\
If non-intentional & $\mathrm{n}=41(\%)$ \\
Accidental & $17(41.4)$ \\
Snakebite & $09(22.0)$ \\
Bee stings & $15(36.5)$ \\
Route of poisoning & \\
Ingestion & $108(81.2)$ \\
Other routes & $25(18.8)$ \\
Ingestion physical form & $\mathrm{n}=108(\%)$ \\
Solid & $65(60.2)$ \\
Liquid & $38(35.2)$ \\
Gas & $05(4.6)$ \\
Intended use of poisoning & $\mathrm{n}=91(\%)$ \\
Medication & $47(51.6)$ \\
Insecticides & $19(20.9)$ \\
Rodenticides & $12(13.2)$ \\
Household chemicals & $31(34.0)$ \\
\hline
\end{tabular}

During the time of admission, $62.4 \%$ received first aid with gastric lavage and activated charcoal. At the time of ICU admission based on the vital signs and stability of the patient, the potential treatment included specific (24\%), supportive (52.71\%), and symptomatic $(23.3 \%)$. Supportive and symptomatic treatment included the administration of therapeutic drugs such as gastroprotective agents, antibiotics, antiemetic's, nonsteroidal anti-inflammatory drugs, and central nervous system agents. The notable factors which influence the outcomes in patients with poisoning were correlated with the PSS in which $60.90 \%$ presented with mild symptoms, $15.78 \%$ moderate symptoms, and $4.51 \%$ with severe and fatal symptoms (Table 3 ).

With respect to Table 4, patterns of poisoning were determined by reason, route and location of exposure, intended use, and first aid; hence, the results demonstrated no significance with age and gender $(\mathrm{p}<0.005)$. In light with the reason of exposure and marital status, study participants who were single (OR: 18.525) were more likely to have intentional poisoning when compared to married and other groups (widower and retired). In relation with the route of exposure, no statistical significance was seen, but with regard to physical form, higher ingestion of physical forms was significantly observed in both single (OR: 4.5) and married (OR: 3).

\section{DISCUSSION}

Understanding the epidemiology of acute poisoning, the dominance of poisonous agents and severity scoring systems (GCS, PSS) are of major importance for providing immediate management and intense monitoring of treatment procedures in patients admitted to the emergency centers. Thus, the prospective observational study with a total of 133 patients aimed to provide the data regarding patterns and outcomes of poisoning. 
With regard to the demographic variables (Table 1), the findings of our study reported a mean age of $27.76 \pm 15.5$ with higher incidence in age groups of $<30$ years (59.3\%) that resembles to a study where $41 \%$ belonged to the same age group that could be related to factors of progression in younger generations, family members becoming less supportive of their choices pertaining to financial independence, marriage age, failure in examinations, premarital sex, rehabilitation, and physical and sexual abuse [9]. Contrary to our findings was a study conducted in Nepal where poisoning incidents were predominant in age groups of $>40$ years [10]. As gender differences were observed, females $(52.6 \%)$ and outnumbered males $(47.3 \%)$ which were contrary to other studies [11]; nevertheless, the findings of studies conducted by other researchers correlated to our findings [12]. Financial distress, family issues, debt, extramarital affairs, emotional neglect, and marital disharmony increase the poisoning attempts in married groups similar to the results of our study (49.6\%) [13].

Data from several national and international studies correlated with the present findings (Table 2), intentional poisoning is the main cause followed by accidental exposure (41.4\%) which could have occurred due to consumption of poison mistaken as medicine, accidental spraying of chemical substances, and poisonous agents accidentally consumed by children [9-15].

\section{Table 3: Hospital attendance pattern of the poisoning of the} study participants

\begin{tabular}{ll}
\hline Variables & $\mathbf{n = 1 3 3}(\mathbf{\%})$ \\
\hline Hospitalization time after exposure & \\
$\leq 60 \mathrm{~min}$ & $45(33.8)$ \\
$>60 \mathrm{~min}$ & $88(66.2)$ \\
Reason for delay, if 60 min & \\
$\quad$ Traffic/transport & $67(76.2)$ \\
Medical referral & $06(06.8)$ \\
Others & $15(17.0)$ \\
Location of exposure & \\
Home & $109(82.0)$ \\
Workplace & $14(10.5)$ \\
Others & $10(7.5)$ \\
First aid & \\
Yes & $83(62.4)$ \\
No & $49(36.8)$ \\
Treatment given & \\
Symptomatic & $31(23.3)$ \\
Supportive & $70(52.7)$ \\
Specific & $32(24.0)$ \\
Symptoms due to poisoning & \\
Yes & $108(81.2)$ \\
No & $25(18.8)$ \\
Type of symptoms & \\
Systemic & $76(70.4)$ \\
Local & $16(14.8)$ \\
Both & $16(14.8)$ \\
Poison severity scale & \\
None & $25(18.79)$ \\
Mild & $81(60.9)$ \\
Moderate & $21(15.78)$ \\
Severe/fatal & $06(4.5)$ \\
\hline
\end{tabular}

Oral ingestion was the common route employed in poisoning (81.2\%) while exposure routes such as inhalation, dermal, and ocular did not demonstrate much significance. This came in accordance with a study conducted at a tertiary care hospital where the poison intake was predominantly oral [16]. With regard to the location (82\%), poisonings occurred at home usually in the late evening hours similar to a study conducted by Sulaj et al. [17], the physical forms in which the poisoning agents have been consumed by the victims in higher quantities were in solid forms $(60.2 \%)$.

Consistent with other reports, pharmaceutical medications (44.14\%) were regularly utilized agents for poisoning [18]. The predominance of poisoning with medicinal products might be related to the easy accessibility of different categories of medicines over-the-counter which might have led to the greatest proportion of poisoning by analgesics, antipyretics, sedatives, and antihypertensive in our study. However, these findings were in contrast to the studies in developing countries where organophosphorus compounds constituted the highest number of poisoning agents $[19,20]$.

Besides the medicinal preparations, household chemicals were the most commonly abused agents in poisoning which included products such as acids/detergents, nail polish remover, kerosene, and paint thinner camphor, followed by rodenticides $(13.2 \%)$ and insecticides $(20.9 \%)$. Household cleaning products such as phenol, bleaches, and their derivatives which are stored at home and are easily available are the major contributors to poisoning.

The hospital where the study was conducted is a 1200 bedded hospital catering to the needs of the people in the surroundings and thus patients are referred from different hospitals or rural areas. Hence, arrival to the hospital varied in between $>1 \mathrm{~h}$ and greater $<1 \mathrm{~h}$ and, in our study, results showed that $66.2 \%$ arrived at the hospital in a time duration greater than an hour. In this context, studies conducted by researchers reported the time interval between the intake of poison and arrival of the victim to the hospital to be more than $1 \mathrm{~h}$ while in a study conducted by Paudyal et al., more than one-third of the patients arrived within an hour of exposure (37\%) [21-23].

Transport- and traffic-related issues (76.2\%), the referral from other local hospitals and emergency centers due to lack of treatment facilities $(6.8 \%)$ was the frequently observed reasons for a delay in admission.

The clinical presentation of the patients depends on the poisoning agent involved and $81.2 \%$ of patients presented with symptoms while $18.8 \%$ remained asymptomatic. Chief presenting complaints were systemic (70.4\%), local $(14.8 \%)$, or both $(14.8 \%)$, and systemic symptoms comprised gastrointestinal manifestations such as nausea, vomiting, and abdominal pain followed by neurological, cardiovascular, and other manifestations (Fig. 1). Our study findings resembled a study conducted in Qassim region of Saudi Arabia, where nausea and vomiting were the most common symptoms [24].

Considering the result of this study, about $62.4 \%$ received first aid in which frequently administered techniques were gastric lavage along with activated charcoal and emesis irrespective of the nature and type of poison consistent with the results obtained in other studies [8,9]. People

Table 4: Demographic characteristics association with pattern of poisoning

\begin{tabular}{|c|c|c|c|}
\hline \multirow[t]{2}{*}{ Variable } & Reason of exposure & \multirow{2}{*}{$\begin{array}{l}\text { Route of exposure } \\
\text { OR: } 95 \% \text { CI }\end{array}$} & \multirow{2}{*}{$\begin{array}{l}\text { Physical form } \\
\text { OR: } 95 \% \text { CI }\end{array}$} \\
\hline & OR: $95 \% \mathrm{CI}$ & & \\
\hline Age & $0.523(0.14-1.94)$ & $1.232(0.21-7.09)$ & $1.182(0.47-2.92)$ \\
\hline Gender & $0.722(.231-2.25)$ & $1.115(0.48-2.54)$ & $0.717(0.33-1.52)$ \\
\hline \multicolumn{4}{|c|}{ Marital status } \\
\hline Single & $18.525(5.33-64.31)^{*}$ & $1.206(0.27-5.38)$ & $4.2(1.33-13.25)$ \\
\hline Married & $10.506(3.39-32.54)^{*}$ & $0.630(0.16-2.46)$ & $3.000(1.02-8.810)$ \\
\hline
\end{tabular}


who did not receive first aid were probably brought to the hospital directly as they might have been geographically closer to the hospital and hence received appropriate treatment when compared to others.

The important factors influencing the outcomes of poisoning depend on the treatment provided to the patient. In our hospital setting, the treatment modality for acute poisoning was found to be virtually similar, which included prevention of further absorption and increase in the elimination of poisonous agent. Supportive care (52.67\%) was the mainstay of management in the majority of poisoning patients. Similar findings were observed in the study done in which symptomatic and supportive care remained the mainstay of management. The symptomatic treatment included drugs to reduce gastric acid secretion, antiemetics, antibiotics (Fig. 2), and supportive care included airway, breathing, circulation, resuscitation with intravenous fluids, and use of (renal replacement therapy) renal replacement therapy [11].

In our study, PSS was utilized to predict the severity of poisoning. Based on the PSS, patients with minor symptoms were $60.90 \%$, majority of the victims recovered, and the number of deaths was minimalistic (Table 3) which was on par with a study conducted in Nepal where mortality rate was 5\% [23]. Patients who were discharged against medical advice from emergency wards were mainly due to the unavailability of beds and cost of the hospitalization stay. All the patients who were discharged were hemodynamically stable. However, due to the nature and the timing of the study, we were unable to follow-up the discharge patients.

Logistical regression analysis model was adopted to determine the significant factors influencing the patterns of poisoning. The variables entered in this model were reason of exposure, route of exposure, location of exposure, physical form, intended use, and first aid. The pattern of poisoning showed no significance with age and gender while the reason of exposure was compared with marital status, study participants who were single (OR: 18.525) were more likely to have intentional poisoning when compared to married and other groups (widower and retired). In relation with the route of exposure, no statistical significance was seen, but with regard to physical form, higher ingestion of physical forms was significantly observed in both the single (OSR: 4.5) and married (OR: 3) (Table 4).

\section{CONCLUSION}

This prospective study has managed to give additional insight into the epidemiology and outcomes of acute poisoning. The reason for poisoning showed significance with marital status $(p<0.005)$ and intentional poisoning by pharmaceutical products followed by household products predominantly in their solid forms at their homes attributed to the significant number of cases. Symptomatic and supportive care was the mainstay of management. Appropriate use of poison severity indices, i.e., PSS score has demonstrated excellent correlation with clinical outcomes and a significant number of patients with mild symptoms recovered.

\section{Future insights}

- Legislations should be implemented to ban over-the-counter sales of pharmaceutical drugs such as narcotic drugs and poisonous agents, thus reduced access can cause a decline in the incidence of deliberate self-harm.

- As marital status demonstrated a strong significance in poisoning, implementing public health strategies along with interactive preventive programs among these groups would influence their mindset and reduce the chances for their deliberate self-harm.

- In addition, workshops and counseling programs on drug poisoning and public safety are recommended in increasing the awareness about support programs for mentally disturbed people.

- Educating the general public on first aid measures that can be implemented until transfer to the hospital or the arrival of medical emergency can reduce the mortality rate.

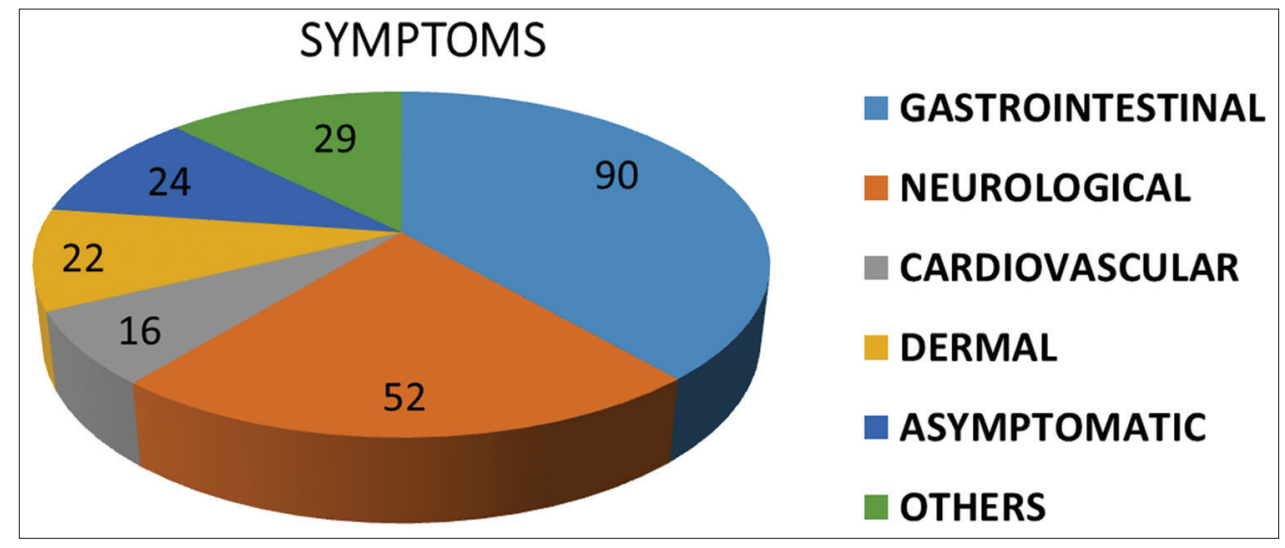

Fig. 1: Distribution of symptoms

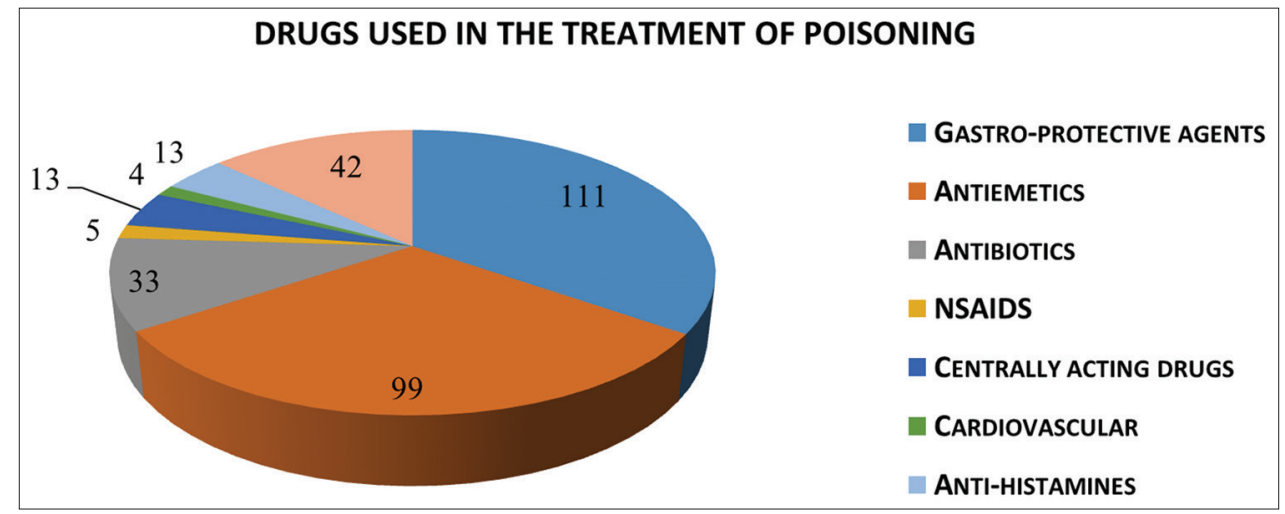

Fig. 2: Distribution of therapeutic drugs administered 


\section{ACKNOWLEDGMENT}

We acknowledge Dr. V. Madhavan, Dean, Dr. E. Maheswari, Professor and Head of the Department of Pharmacy Practice, Faculty of Pharmacy, M. S. Ramaiah University of Applied Sciences, Dr. Vijay Sharma, and Dr. Aruna C Ramesh, Head of the Department Emergency Medicine MS Ramaiah Memorial and Teaching Hospitals, Bangalore.

\section{FUNDING OR OTHER COMPETING INTERESTS}

This research did not receive any specific grant from funding agencies in the public, commercial, or not-for-profit sectors.

\section{DISCLOSURES}

The authors declare no conflict of interest. All the authors declare that they had no financial, personal relations toward other organizations whose interest could have affected the content of the article in either positive or negative way.

\section{AUTHOR'S CONTRIBUTION}

Dr. Devi Revathi and Dr. Sathvika wrote the primary draft of this paper, which was edited by Dr. Lakshmi Prasanna Marise for essential content. Dr. Aruna C Ramesh helped with the review of the paper for improved quality. All the authors reviewed and provided comments on further iterations.

\section{CONFLICTS OF INTEREST}

"The author(s) declare(s) that there are no conflicts of interest regarding the publication of this paper."

\section{REFERENCES}

1. Jesslin J, Adepu R, Churi S. Assessment of prevalence and mortality incidences due to poisoning in a South Indian tertiary care teaching hospital. Indian J Pharm Sci 2010;72:587-91.

2. Datir SB, Petkar M, Farooqui JM, Makhani CS, Hussaini SN, Chavan KD, et al. Study of outcome in acute poisoning cases in rural region of Western Maharashtra. J Forensic Leg Med Title 2015;24:1-7.

3. National Crime Records Bureau. Suicides in India-Accidental Deaths and Suicides in India. 2015. Available from: http://www.ncrb.gov.in/. [Last accessed on $2018 \mathrm{Feb} 27$ ].

4. Centre for Disease Control and Prevention NCHS Data on Drug Poisoning Deaths August. 2017. Available from: https://www.cdc.gov/ nchs/data/factsheets/factsheet_drug_poisoning.htm. [Last accessed on $2018 \mathrm{Feb} 27]$.

5. Banerjee I, Tripathi SK, Roy AS. Clinico-epidemiological profile of poisoned patients in emergency department: A two and half year's single hospital experience. Int J Crit Illn Inj Sci 2014;4:14-7.

6. Senarathna L, Jayamanna SF, Kelly PJ, Buckley NA, Dibley MJ, Dawson AH. Changing epidemiologic patterns of deliberate selfpoisoning in a rural district of Sri Lanka. BMC Public Health 2012;12:593.
7. Singh O, Javeri Y, Juneja D, Gupta M, Singh G, Dang R. Profile and outcome of patients with acute toxicity admitted in intensive care unit: Experiences from a major corporate hospital in urban India. Indian $\mathbf{J}$ Anaesth 2011;55:370-4.

8. Teklemariam E, Tesema S, Jemal A. Pattern of acute poisoning in Jimma University Specialized Hospital, South West Ethiopia. World J Emerg Med 2016;7:290-3.

9. Khan P, Kumar M, Nousheen B. A study on treatment pattern and outcomes of poisoning cases in a tertiary care and government district hospital. Int J Pharm Pharm Sci 2017;9:193-7.

10. Marahatta SB, Singh J, Shrestha R, Koju R. Poisoning cases attending Emergency department in Dhulikhel hospital-Kathmandu university teaching hospital. Kathmandu Univ Med J 2009;7:152-6.

11. Anthony L, Kulkarni C. Patterns of poisoning and drug overdosage and their outcome among in-patients admitted to the emergency medicine department of a tertiary care hospital. Indian J Crit Care Med 2012;16:130.

12. Bakhaidar M, Jan S, FarahatF, Attar A, Alsaywid B,Abuznadah W. Pattern of drug overdose and chemical poisoning among patients attending an emergency department, western Saudi Arabia. J Community Health 2015;40:57-61

13. Siwach SB, Gupta A. The profile of acute poisonings in HarayanaRohtak study. J Assoc Physicians India 1995;43:756-9.

14. Asawari R, Atmaram P, Bhagwan K, Priti D, Kavya S, Jabeen GA. Toxicological pattern of poisoning in urban hospitals of Western India. J Young Pharm 2017;9:315-20.

15. Ramanath KV, Kumar HD. Study the assessment of poisoning cases in a rural tertiary care teaching hospital by a clinical pharmacist. Asian J Pharm Clin Res 2012;5:138-41.

16. Koylu R, Dundar ZD, Koylu O, Akinci E, Akilli NB, Gonen MO, et al. The experiences in a toxicology unit: A review of 623 cases. J Clin Med Res 2014;6:59-65.

17. Sulaj Z, Prifti E, Demiraj A, Strakosha A. Early clinical outcome of acute poisoning cases treated in intensive care unit. Med Arch 2015;69:400-4.

18. Moradi M, Ghaemi K, Mehrpour O. A hospital base epidemiology and pattern of acute adult poisoning across Iran: A systematic review. Electronic Physician 2016;8:2860-70.

19. Mittal N, Shafiq N, Bhalla A, Pandhi P, Malhotra S. A prospective observational study on different poisoning cases and their outcomes in a tertiary care hospital. SAGE Open Med 2013;1:2050312113504213.

20. Ahuja H, Mathai AS, Pannu A, Arora R. Acute poisonings admitted to a tertiary level intensive care unit in Northern India: Patient profile and outcomes. J Clin Diagn Res 2015;9:UC01-4.

21. Al-Barraq A, Farahat F. Pattern and determinants of poisoning in a teaching hospital in Riyadh, Saudi Arabia. Saudi Pharma J 2011:19:57-63.

22. Mbarouk GS, Sawe HR, Mfinanga JA, Stein J, Levin S, Mwafongo V, et al. Patients with acute poisoning presenting to an urban emergency department of a tertiary hospital in Tanzania. BMC Res Notes 2017;10:482.

23. Paudyal BP. Poisoning: Pattern and profile of admitted cases in a hospital in central Nepal. J Nepal Med Assoc 2005;44:92-6.

24. Moazzam M, Al Saigul AM, Naguib M, Al Alfi MA. Pattern of acute poisoning in Al-Qassim region: A surveillance report from Saudi Arabia, 1999-2003. East Mediterr Health J 2009;15:1005-10. 